\title{
Pleural malignant mesothelioma and non- occupational exposure to asbestos in Casale Monferrato, Italy
}

Corrado Magnani, Benedetto Terracini, Cristiana Ivaldi, Mario Botta, Angelo Mancini, Alberto Andrion
Cancer Epidemiology Unit, Local Health Authority and University of Torino, Torino, Italy

C Magnani

B Terracini

C Ivaldi

Special Project on Asbestos Cement M Botta

Public Health Unit, Local Health

Authority, Casale

Monferrato, Italy

A Mancini

Division of

Pathological

Anatomy, City

Hospital, Asti, Italy

A Andrion

Correspondence to:

Dr Corrado Magnani,

Cancer Epidemiology Unit,

Via Santena 7, 10126

Torino, Italy.

Accepted 30 January 1995

\begin{abstract}
Objectives-To assess and quantify the occurrence of pleural malignant mesotheliomas in people who neither experienced occupational exposure to asbestos nor were married to (or known to live with) workers exposed to asbestos in the workplace. The study was conducted in the area of the local health authority of Casale Monferrato, in north western Italy, where a large factory that produced asbestos cement was active up to 1985 . No other major activities related to asbestos have ever been present in the area.
\end{abstract}

Methods-A retrospective survey covering the period 1980 to 1991 identified 126 incident pleural malignant mesotheliomas histologically diagnosed among residents in the local health authority (population at the 1981 census 98000 ). Submission of 83 of 95 cases diagnosed during 1980-9 for revision by a panel of five expert pathologists led to the exclusion of 21. The 31 cases diagnosed in 1990-1 were not submitted for revision. For 64 of the 105 retained cases, information derived from different sources (rosters of the employees in the asbestos cement factory dated back to 1907 , list of their spouses, clinical records) did not suggest occupational or paraoccupational exposure to asbestos.

Results-Incidence excludes cases for which there was some suggestion of occupational or paraoccupational exposure to asbestos. Incidence of histologically confirmed malignant mesothelioma among residents in the local health authority (annual $\times 100$ 000; age adjusted) was 4.2 in men and 2.3 in women (based on 26 and 18 cases respectively). In both sexes, rates in 1985-9 were higher than in the previous quinquennium. Corresponding estimates for 1990-1 (based on unrevised diagnoses) suggest similar rates in men and women.

Conclusion-Rate ratios which are four to six times those measured by conventional Italian cancer registries can hardly be totally explained by bias produced by lack of recognition of occupational or paraoccupational exposure. The problem of proving this type of negative data is common to other circumstances of alleged cancer clusters of environmental (non occupational) origin.

(Occup Environ Med 1995;52:362-367)

Keywords: pleural malignant mesothelioma; asbestos; non-occupational exposure; environmental cancer

The largest Italian factory that produces asbestos cement (owned by Eternit) was active in the town of Casale Monferrato in north western Italy from 1907 to 1985 .

Mortality of workers in the factory has been reported. From 1964 to 1986,117 workers of both sexes died from lung cancer, 89 from asbestosis and 43 from pleural malignancies $v$ corresponding expected figures of $42.4,0.1$, and 1.3.' An excess of pleural malignancies (based on six cases) was also found in wives of asbestos cement workers although they had not been employed in the plant. ${ }^{2}$

In the 1981 census, $^{3}$ populations of the administrative area corresponding to the local health authority and of Casale Monferrato (the main town in the authority) were 97800 and 41700 respectively. The whole area is away from the hinterland of large industrial cities. Its main productive activities have been agriculture, asbestos cement production, cement production, and light mechanical industry (printing machinery, refrigerators, etc). Apart from Eternit, no other asbestos industries or industrial activities likely to entail notable use of asbestos, such as chemical or car industries, were ever present in Casale Monferrato or other towns within the local health authority. At both the 1961 and 1971 censuses, the textile and chemical industries and metal works employed less than $1 \%$, less than $1 \%$, and $10 \%$ of the population, respectively. ${ }^{4}$ In 1960 , in 1970, and in 1980 the asbestos cement factory employed 1650, 1200 , and 800 workers. In 1980 it reported an output of 200000 tonnes of asbestos cement products.

The Eternit factory was located less than $1000 \mathrm{~m}$ from the town centre of Casale Monferrato. Because of the short distance and of the direction of winds, airborne asbestos contamination was probable within the town. Measurements outside the factory started only in 1984: in the town, asbestos concentrations (fibres longer than $5 \mu \mathrm{m}$ ) were in the range of: less than 0.4 (detection limit) to $19 \cdot 1 \mathrm{f} / 1$, with mean values ranging from 1 to $11 \cdot 1 \mathrm{f} / 1$. These 
fibre counts refer to SEM analysis with fibre identification by energy dispersive $x$ ray analysis. ${ }^{6}$ The management has reported that as late as 1980 crocidolite accounted for $10 \%$ of the total amount of asbestos that was used. ${ }^{1}$

In 1984-9 the local health authority annual mortality (age adjusted to the 1981 Italian population $\times 100000$ ) for pleural malignancy was 15.9 among men and 5.7 among women, based on 60 and 33 deaths, respectively. ${ }^{7}$

Asbestos (particularly crocidolite and amosite), erionite, and, to a lesser degree, ionising radiation are the only known causes of malignant mesothelioma in humans. ${ }^{8}$ We have systematically surveyed incident malignant mesotheliomas of the pleura, histologically diagnosed since 1980 , of residents in the local health authority, and less than a half of them had been employed in the asbestos cement plant. ${ }^{9}$ Thus it is reasonable to hypothesise that some malignant mesotheliomas might have been caused by asbestos pollution in the general atmosphere, as reported elsewhere. ${ }^{1011}$ To evaluate the soundness of the hypothesisand because histological diagnoses of malignant mesothelioma may be problematic ${ }^{12}$ findings of a preliminary report have now been extended in time, ${ }^{9}$ most cases diagnosed in the 1980s have been reviewed by a panel of pathologists and more sensitive criteria have been used to identify occupational or paraoccupational (domestic, for people who share their household with asbestos cement workers) exposure to asbestos.

\section{Material and methods \\ COLLECTION OF CASES}

Histological diagnoses of malignant mesotheliomas of the pleura recorded since 1980 in residents in the local health authority were retrospectively identified by a medical doctor who perused the registers of the pathology units in the hospital of Casale Monferrato and six other hospitals (including three teaching hospitals) whose catchment areas include residents in the local health authority. It is believed that retrieval of cases was exhaustive. No systematic effort has been made to identify cases not diagnosed histologically. These have not been considered in the present analyses. The survey identified 126 people with incident pleural malignant mesotheliomathat is, 95 diagnosed in $1980-9$ and 31 in 1990-1.

\section{CONFIRMATION OF THE HISTOLOGICAL} DIAGNOSIS

Eighty three malignant mesotheliomas diagnosed before 1989 were reviewed by five expert pathologists. ${ }^{13}$ The remaining 12 were excluded because the pathology laboratory either did not submit any material (four cases), submitted it too late (two cases), or the case was identified during the update of the survey (six cases). Each pathologist independently reviewed the slides for each case and rated his diagnosis according to an ordinal scale, definite, probable, possible, improb- able, and definitely not malignant mesothelioma, according to the criteria defined by Jones et al. ${ }^{14}$ There was no consensus meeting. Of the 83 reviewed cases, 62 were retained as they were rated either as definite or probable malignant mesothelioma by three or more reviewers (60 cases) or as probable or definite malignant mesothelioma by two reviewers and possible malignant mesothelioma by all the remaining three (two cases).

VERIFICATION OF EXPOSURE TO ASBESTOS

Patients with malignant mesothelioma who had ever been employed in Eternit or were wives of asbestos cement workers were identified in either the roster of employees of the plant or in the cohort assembled for a previous study. ${ }^{2}$ The completeness of the roster and the accuracy of the procedure used for identification were validated in two ways.

Firstly, the roster of employees was checked against complete occupational histories collected for individual workers within an ongoing case-control study on pleural malignant mesothelioma. That study is based on interviews with the next of kin of residents from the local health authority who died in 1987 to 1990 . Among 129 subjects whose questionnaire was reviewed (blindly for casecontrol status), there was agreement between the two sets of data for 128, 12 of whom had worked at Eternit and 116 had not. The exception was one person whose employment at Eternit was reported in the roster but not in the questionnaire.

Secondly, clinical records were available for 116 of 126 subjects diagnosed to have malignant mesothelioma (before revision). It is generally acknowledged that information given on clinical documents about occupational anamneses is limited: however, this was not a good reason for not using them as another set of data against which completeness of the rosters of Eternit employees and their spouses could be estimated. Out of 31 cases of malignant mesothelioma included in the roster of Eternit workers, 24 were correctly quoted as such in the clinical record and two were reported as exposed to asbestos. On the contrary, only two cases that were reported in the clinical record as employed in Eternit for short periods (six and 18 months) did not appear in the roster of Eternit workers (one was also reported to have been compensated for asbestosis). In the computation of rates, these two subjects were considered as occupationally exposed.

Also, eight clinical records mentioned engagement (with no further details) for unspecified periods in occupations that, according to the scientific literature ${ }^{15}$ might have entailed exposure to asbestos: two construction workers, two car mechanics, two electricians, one worker in cable making, and one metal worker with exposure to asbestos. Similarly, clinical records reported domestic exposure to asbestos for two subjects. All these cases were considered to have been occupationally or paraoccupationally exposed to asbestos. 
Table 1 Confirmed cases of pleural malignant mesotheliomas diagnosed in 1980-9 among residents in the local health authority of Casale Monferrato (and in three subareas) for whom there was no suggestion of occupational or

paraoccupational exposure to asbestos (rates reported by the Cancer Registry of Varese ${ }^{14}$ and by the Italian Cancer

Registries ${ }^{22}$ are included for comparison: rates are annual $\times 100$ 000; age adjusted on the 1981 Italian population over the range $0+$ )

\begin{tabular}{|c|c|c|c|c|c|c|}
\hline & $\begin{array}{l}\text { Local health } \\
\text { authority } \\
\text { of Casale } \\
\text { Monferrato }\end{array}$ & $\begin{array}{l}\text { Town of } \\
\text { Casale } \\
\text { Monferrato }\end{array}$ & $\begin{array}{l}\text { Adjacent } \\
\text { towns }\end{array}$ & $\begin{array}{l}\text { Other } \\
\text { towns within } \\
\text { the local } \\
\text { health authority }\end{array}$ & $\begin{array}{l}\text { Province } \\
\text { of } \\
\text { Varese }\end{array}$ & $\begin{array}{l}\text { Pool of } \\
\text { Italian } \\
\text { cancer } \\
\text { registries }\end{array}$ \\
\hline \multicolumn{7}{|l|}{ Men: } \\
\hline $\begin{array}{l}\text { nate }(95 \% \text { CI }) \\
\text { Rat }\end{array}$ & $\stackrel{26}{4 \cdot 2(2 \cdot 4-6 \cdot 0)}$ & $\stackrel{20}{8 \cdot 2(4 \cdot 3-12 \cdot 2)}$ & $\begin{array}{l}4 \\
3.4(0 \cdot 0-8 \cdot 0)\end{array}$ & $\begin{array}{l}2 \\
0.6(0.0-1.6)\end{array}$ & $\stackrel{18}{1 \cdot 0(-)}$ & $\begin{array}{l}159 \\
1 \cdot 8(-)\end{array}$ \\
\hline $\begin{array}{l}\text { Population at } \\
1981 \text { census }\end{array}$ & & & & & & \\
\hline $\begin{array}{l}\times 1000 \\
\end{array}$ & $46 \cdot 7$ & $19 \cdot 6$ & $8 \cdot 1$ & 19.0 & & \\
\hline Women: & & & & & & \\
\hline $\begin{array}{l}\text { n } \\
\text { Rate }(95 \% \text { CI })\end{array}$ & $\stackrel{18}{2 \cdot 3(1 \cdot 1-3 \cdot 5)}$ & ${ }^{16} \cdot 1(2 \cdot 4-7 \cdot 8)$ & $\begin{array}{l}0 \\
-\end{array}$ & $\begin{array}{l}2 \\
0.7(0.0-1.9)\end{array}$ & $\begin{array}{l}7 \\
0 \cdot 3(-)\end{array}$ & $\begin{array}{l}70 \\
0.6(-)\end{array}$ \\
\hline $\begin{array}{l}\text { Population at } \\
1981 \text { census } \\
\times 1000\end{array}$ & $51 \cdot 1$ & $22 \cdot 1$ & $8 \cdot 8$ & $20 \cdot 3$ & & \\
\hline
\end{tabular}

STATISTICAL ANALYSES

As only cases diagnosed in 1980-9 were submitted for diagnostic revision, rates have been computed separately for $1980-9$ and for 1990-1. The 12 cases that were not traced in time for revision were part of the 1980-9 group. Incidence was computed for the entire local health authority and for three subareas: the town of Casale Monferrato, the towns adjacent to Casale Monferrato-that is, those sharing boundaries with it-and the other towns of the local health authority. Population figures (age and sex specific) were available for each municipality from the 1981 census $^{3}$ and from estimates for each year up to 1987. ${ }^{16}$ The 1987 data were used as proxies for the population structure for age and sex in the following four years, during which no major changes in total population occurred.

The rates reported in table 1 and elsewhere in the text excluded cases for which occupational or paraoccupational exposure to asbestos was known or suggested from available information - that is, cases mentioned in table 2. Rates were standardised for age with the 1981 Italian population ${ }^{3}$ in the age range $0+$, broken down in quinquennial age groups. Ninety five per cent confidence intervals (95\% CIs) of age standardised rates have been estimated as previously described. ${ }^{17}$

Rates have been compared with those produced by the Cancer Registry of Varese in $1983-7^{18}$ and with a weighted average of rates estimated by the nine active Italian Cancer Registries $^{19}$ that serve a total of about $10 \%$ of

Table 2 Distribution of incident pleural mesothelioma (1980-91) according to evidence of occupational or paraoccupational exposure to asbestos (see text for details on assessment of exposure and definitions)

\begin{tabular}{lcc}
\hline & $\begin{array}{l}\text { Men } \\
n(\%)\end{array}$ & $\begin{array}{l}\text { Women } \\
n(\%)\end{array}$ \\
\hline $\begin{array}{l}\text { Occupational record in the asbestos cement plant } \\
\text { Wife of asbestos cement worker (no occupation in the same plant) }\end{array}$ & $19(30 \cdot 2)$ & $\begin{array}{l}9(21 \cdot 4) \\
1(1 \cdot 6)\end{array}$ \\
$\begin{array}{l}\text { None of the above mentioned but asbestosis or asbestos } \\
\text { cement mentioned in the clinical record }\end{array}$ & $2(3 \cdot 2)$ & $-(-)$ \\
$\begin{array}{l}\text { None of the above mentioned but domestic exposure } \\
\text { mentioned in the clinical record }\end{array}$ & $-(-)$ & $2(3 \cdot 2)$ \\
$\begin{array}{l}\text { None of the above mentioned but occupation reported } \\
\text { in clinical record may have entailed asbestos exposure }\end{array}$ & $7(11 \cdot 1)$ & $1(1 \cdot 6)$ \\
$\begin{array}{l}\text { None of the above mentioned } \\
\text { Total }\end{array}$ & $35(55 \cdot 6)$ & $29(46 \cdot 0)$ \\
\hline
\end{tabular}

${ }^{\star}$ List in materials and methods. the Italian population. The range of incidences measured by the Italian Cancer Registries $(\times 100000$ person-years, age adjusted to the 1981 Italian population) spans from 0.6 to 7.0 among men and 0.2 to 1.7 among women. In both sexes, the highest rates are found in Genova and Trieste: both are coastal cities with harbours and dockyards.

\section{Results}

Our survey originally identified 126 residents in the local health authority to whom a malignant mesothelioma of the pleura was histologically diagnosed in 1980-91. As explained above, out of 95 cases diagnosed in 1980-9 23 were not confirmed; rates for this period include the 62 revised cases and 12 cases that were not submitted for histological review. Of the 21 rejected cases, those that reported occupational or paraoccupational exposure were three out of 10 men and five out of 11 women. None of the 31 malignant mesotheliomas diagnosed in 1990-1 underwent review by the panel of expert pathologists.

Table 3 shows the distribution of the 105 cases retained by whether or not occupational or paraoccupational exposure to asbestos was reported, sex, age, place of birth, year of diagnosis, source of the histological specimen, and histological type. Distribution of these variables was similar in the two groups: differences in sex distribution and proportion of necropsy diagnoses are interesting but not significant. Also not significant was the higher proportion of women originating from outside the local health authority among the nonexposed cases. The cases not submitted for histological review (for the reasons already given) were 15 among those occupationally or paraoccupationally exposed and among the others.

Table 2 describes the distribution of the cases retained by the sources of information on occupational or paraoccupational exposure to asbestos. Table 1 reports incidences in 1980-9 computed for the cases with no suggestion of such exposure (the last category in table 2). Table 1 also reports the incidences from the Italian Cancer Registries. 
Table 3 Distribution of incident pleural mesothelioma in (1980-91) (see text for definition of occupational or paraoccupational exposure to asbestos)

\begin{tabular}{|c|c|c|}
\hline & \multicolumn{2}{|c|}{$\begin{array}{l}\text { Occupational or paraoccupational } \\
\text { exposure to asbestos }\end{array}$} \\
\hline & $\begin{array}{l}\text { Yes } \\
n(\%)\end{array}$ & $\begin{array}{l}\text { No } \\
n(\%)\end{array}$ \\
\hline \multicolumn{3}{|l|}{ Sex: } \\
\hline Men & $28(68 \cdot 3)$ & $35(54 \cdot 7)$ \\
\hline Women & $13(31 \cdot 7)$ & $29(45 \cdot 3)$ \\
\hline \multirow{2}{*}{\multicolumn{3}{|c|}{$\begin{array}{l}\text { Age: } \\
\text { Men. }\end{array}$}} \\
\hline & & \\
\hline Mean (SD) & $63.4(12.4)$ & $62 \cdot 5(13 \cdot 1)$ \\
\hline Range & $(32-87)$ & $(30-81)$ \\
\hline \multicolumn{3}{|l|}{ Women: } \\
\hline Mean (SD) & $60 \cdot 8(8 \cdot 3)$ & $68.9(10 \cdot 8)$ \\
\hline Range & $(49-80)$ & $(45-85)$ \\
\hline \multicolumn{3}{|l|}{ Place of birth: } \\
\hline Local health authority & $17(41 \cdot 5)$ & $27(42 \cdot 2)$ \\
\hline Elsewhere & $11(26 \cdot 8)$ & $8(12 \cdot 5)$ \\
\hline \multicolumn{3}{|l|}{ Women: } \\
\hline Local health authority & $10(24 \cdot 4)$ & $15(23.4)$ \\
\hline Elsewhere & $3(7 \cdot 3)$ & $14(21.9)$ \\
\hline \multicolumn{3}{|l|}{ Period of diagnosis: } \\
\hline $1980-4$ & $7(17 \cdot 1)$ & $13(20 \cdot 3)$ \\
\hline $1985-9$ & $23(56 \cdot 1)$ & $31(48 \cdot 4)$ \\
\hline $1990-1$ & $11(26 \cdot 8)$ & $20(31 \cdot 3)$ \\
\hline \multicolumn{3}{|l|}{ Hospital where diagnosed: } \\
\hline Local & $16(39 \cdot 0)$ & $28(43 \cdot 8)$ \\
\hline Teaching & $21(51 \cdot 2)$ & $33(51 \cdot 6)$ \\
\hline Other & $4(9 \cdot 8)$ & $3(4 \cdot 7)$ \\
\hline \multicolumn{3}{|l|}{ Source of pathological tissue: } \\
\hline Necropsy & $8(19 \cdot 5)$ & $5(7 \cdot 8)$ \\
\hline Surgery & $7(17 \cdot 1)$ & $13(20 \cdot 3)$ \\
\hline Thoracoscopy & $15(36 \cdot 6)$ & $33(51 \cdot 6)$ \\
\hline Needle biopsy & $6(14 \cdot 6)$ & $5(7 \cdot 8)$ \\
\hline Unspecified biopsy & $5(12 \cdot 2)$ & $8(12 \cdot 5)$ \\
\hline \multicolumn{3}{|c|}{ Histological type (original diagnosis): } \\
\hline Epithelial & $13(31 \cdot 7)$ & $28(43 \cdot 8)$ \\
\hline Mixed & $9(22 \cdot 0)$ & $11(17.9)$ \\
\hline Fibrosarcomatous & $3(7 \cdot 3)$ & $5(7 \cdot 8)$ \\
\hline Unspecified & $16(39 \cdot 0)$ & $20(31 \cdot 3)$ \\
\hline Total & 41 & 64 \\
\hline
\end{tabular}

Of the 44 cases included in table 1,13 (eight men and five women) were diagnosed during 1980-4 and 31 (18 and 13) during 1985-9. In men, annual age adjusted rates $\times 100000(95 \% \mathrm{CI})$ were $2 \cdot 4(0 \cdot 6-4 \cdot 3)$ and $5.9(2 \cdot 9-9 \cdot 0)$ respectively. Estimates for women were $1 \cdot 3(0 \cdot 1-2 \cdot 5)$ and $3 \cdot 3(1 \cdot 3-5 \cdot 3)$.

Of the 31 cases diagnosed in 1990-1 (table 3), available data suggested occupational or paraoccupational exposure to asbestos for 11 . The other 20 (nine men and 11 women) corresponded to annual age adjusted rates $\times 100000$ of $7 \cdot 4(2 \cdot 0-12.9)$ in men and $7 \cdot 1(2 \cdot 4-11 \cdot 7)$ in women. Corresponding figures among residents in Casale Monferrato were: $15.9(3.6-28 \cdot 3)$ among men and 15.4 (4.9-25.9) among women. As the cases were not submitted for histological revision, these rates are not strictly comparable with those shown in table 1 . To increase comparability we also computed corrected rates, obtained by applying the corresponding proportion of cases accepted among those diagnosed in 1985-9 and submitted for histological revision to the sex specific rates. Resulting rates were 5.9 among men and 5.3 among women in the entire local health authority, and $12 \cdot 8$ and 11.5 in the town of Casale.

Over the whole series of 105 retained cases, 10 (eight men and two women) were younger than 50 at diagnosis. Eight of these were resident in the town of Casale Monferrato. Out of six diagnosed in 1980-9, three were confirmed after review by the panel. An additional one, diagnosed in 1990, was submitted to necropsy (which makes the diagnosis more reliable). On the basis of the available information, four may have experienced occupational exposure to asbestos (in the electromechanical industry, construction work with exposure to asbestos-cement, an electrician, and a worker in the production of electrical cables).

\section{Discussion}

The need to investigate the occurrence of malignant mesotheliomas attributable to nonoccupational exposure to asbestos in the area of Casale Monferrato was prompted by the consideration that the excesses among asbestos cement workers in Eternit and their wives could only partially explain the high mortality and incidence. Previous reports on malignant mesotheliomas in people not occupationally exposed to asbestos consisted of either reviews of occupational histories in necropsy or surgical pathology series or casecontrol studies. ${ }^{10}$ Around the crocidolite mine of Wittenoom, Western Australia, 24 cases of malignant mesothelioma included nine wives and nine children of exposed workers among 4890 people for whom there was no record of employment in the mine. ${ }^{11}$ None of these studies reported rates or number of personyears of observation.

In our study, case identification was satisfactory. We have no suggestions or indications of patients with malignant mesothelioma living in the local health authority of Casale who were diagnosed or treated in hospitals but not included in our survey. Had they occurred rates in the general population and rate ratios $v$ conventional registries would have been underestimated.

The quality of diagnoses was high. Seventy five per cent were diagnosed on specimens obtained at necropsy, surgery, or thoracoscopy. Visual inspection and the possibility of taking multiple biopsies render thoracoscopy as sensitive and reliable as surgery. ${ }^{20}$ Moreover, in another study of ours, ${ }^{13}$ diagnostic agreement on histological sets obtained from surgery or at necropsy paralleled that of material from thoracoscopies. Further, the panel reviewed routinely stained (haematoxylin and eosin) slides only. Preliminary results of an ongoing investigation made on the same material ${ }^{21}$ suggest that systematic use of immunocytochemistry reduces the proportion of slides rated as possible malignant mesothelioma and increases that of slides rated as definite or probable malignant mesothelioma.

In the interpretation of episodes of local excesses of disease postulated to be related to the release of a hazardous contaminant from a plant into the general environment, a major problem is discriminating between the respective roles of occupational and environmental (non-occupational) exposure. In the local health authority of Casale Monferrato, results of measurements outside the factory are inadequate for this purpose so that surrogate data must be used. 
The most obvious surrogate is dichotomous in nature - that is, having or not having experienced exposure to asbestos in the workplace. This issue could be resolved in Casale, because of likely concentration of asbestos related to work in one firm. The exercise entails all the difficulties of proving a negative. A major limitation of our study is that individual occupational or paraoccupational exposure to asbestos was assessed only from databases related to work at Eternit, with the exception of sporadic and debatable information retrieved from clinical records. As no complete anamnesis was collected for the 64 cases for whom there was no suggestion of occupational or paraoccupational exposure to asbestos, opportunities for such exposures during life cannot be ruled out.

The main concern is for exposure to asbestos in workplaces other than Eternit and the extent to which occupational exposures unrelated to the production of asbestos cement can account for the rate ratios being 2.5 to four times greater than those of the Italian Cancer Registries. In fact, these rate ratios are underestimated. Conventional Cancer Registries record cases associated with occupational exposure to asbestos, cases that lack histological confirmation, ${ }^{22}$ and those that have not had histological slides submitted for review by expert pathologists. Thus, compared with rates reported in table 1 , rates of the conventional cancer registry are inflated.

Most Italian Cancer Registries operate in industrialised or harbour areas. On the contrary, as well as the production of asbestos cement, no other industrial activities likely to entail exposure to asbestos have ever been carried out in the local health authority of Casale Monferrato. Of concern in this authority are construction works, for which asbestos cement products have been extensively used. ${ }^{23}$ This putative source of occupational exposure cannot explain the excess of malignant mesotheliomas in women.

Exposure to asbestos during work outside the local health authority cannot be excluded, but mobility of the population seems limited. At least 27 of 35 men and 15 of 29 women with malignant mesothelioma who did not report occupational or paraoccupational exposure to asbestos (table 3) were born in the local health authority (a surrogate foralthough not proof of - stability).

After exclusion of cases occupationally or paraoccupationally exposed, men to women rate ratios of malignant mesothelioma among residents in the local health authority in 1980-9 and in 1990-1 were 1.8 and 1.0 respectively. Thus, it seems that in recent times both sexes are equally affected by an excess of malignant mesothelioma postulated to be associated with pollution of the general environment (and this similarity reinforces the underlying hypothesis). Admittedly, cases diagnosed in the latest period were not submitted for histological revision, but neither sex nor suggestion of exposure seem to be associated with probability of retention or rejection at revision.
Although based on small absolute numbers, rates of malignant mesotheliomas without occupational or paraoccupational exposure were higher in the town of Casale Monferrato and decreased with distance from it. Although this observation may reinforce the hypothesis of a point source of asbestos, it requires further confirmation.

As elsewhere, domestic exposure to asbestos was considered to be relevant as it was customary for workers to bring home their working clothes. In our study, domestic exposure was taken into account only for wives of asbestos cement workers or when it was mentioned in the clinical record. Most likely, domestic exposure in childhood has been missed in the clinical records. The design of our study could not properly consider questions of such detail. More refined methods for quantifying or excluding occupational or paraoccupational exposure are needed to improve our estimates of the risk ensuing from pollution of the general environment. An ongoing case-control study started after the present analyses will provide more adequate estimates of the respective roles of occupational, environmental, and domestic exposure.

We acknowledge the great contribution of Mrs Marinella Nonnato, Dr Giampiero Borgo, and Dr Enzo Borlengo to the collection and quality control of all data and of Mrs Rita Giacometti who edited the text. We are particularly grateful to the heads and staff of the Pathology Departments and of the Archives of Clinical Records of the Hospitals included in the survey. The study was conducted thanks to financial contributions from the International Agency for the Rese tions from the International Agency for the Research on Cancer, the Italian Association for Cancer Research (AIRC), the Administration of the local health authority 76, the Italian Ministry for University and Scientific
EEC-Europe against Cancer Program.

1 Magnani C, Terracini B, Bertolone GP, Castagneto B, Cocito $\mathrm{V}$, De Giovanni $\mathrm{D}$, et al Mortalità per tumori e Cocito V, De Giovanni D, et al. Mortalita per tumori e dell'amianto a Casale Monferrato. Uno studio di coorte storico. Med Lav 1987;78:441-53.

2 Magnani C, Terracini B, Ivaldi C, Botta M, Budel P, Mancini A, Zanetti R. A cohort study on mortality among wives of workers in the asbestos cement industry in Casale Monferrato, Italy. Br F Ind Med 1993;50: 779-84.

3 Istituto Nazionale di Statistica. XII Censimento Generale della Popolazione, 25 Ottobre 1981, Provincia di Alessandria. Roma: ISTAT, 1984:104-15.

4 Istituto Nazionale di Statistica. IV Censimento Generale dell'Industria, 16 Ottobre 1961. Vol II-dati provincialidascicolo 6 (Provincia di Alessandria). Roma: ISTAT, fascicolo 6 .

5 Istituto Nazionale di Statistica. $V$ Censimento Generale dell'Industria, 25 Ottobre 1971. Vol II-dati provincialifascicolo 6 (Provincia di Alessandria). Roma: ISTAT, 1974:64-139.

6 Marconi A, Cecchetti G, Barbieri M. Airborne mineral fibre concentration in an urban area near an asbestoscement plant. In: Bignon J, Peto J, Saracci R, eds. Nonoccupational exposure to mineral fibres. Iyon: IARC, 1989:336-46. (IARC Sci Publ No 90.)

7 Registro Tumori del Piemonte. Mortalità per tumore nelle USL Piemontesi. 1993.

8 Pelnar PV. Further evidence of nonasbestos-related mesothelioma. A review of the literature. Scand $f$ Work Environ Health 1988;14:141-4.

9 Magnani C, Borgo G, Betta GP, Botta M, Ivaldi C, Mollo $\mathrm{F}$, et al. Mesothelioma and non-occupational environmental exposure to asbestos. Lancet 1991;338:50.

10 Gardner MJ, Saracci R. Effects on health of non occupational exposure to airborne mineral fibres. In: Bignon J, Peto J, Saracci R, eds. Non-occupational exposure to mineral fibres. Lyon: IARC, 1989:375-97. (IARC Sci Publ No 90.

1 Hansen JH, De Klerk NH, Eccles $\mathrm{L}$, Musk AW, Hobbs MST. Malignant mesothelioma after environmental exposure to blue asbestos. Int f Cancer 1993;54:578-81.

12 McCaughey WTE, Colby TV, Battifora $\mathrm{H}$, Churg A, Corson JM, Greenberg SD, et al. Diagnosis of diffuse malignant mesothelioma: experience of a US/Canadian malignant mesothelioma: experience of a US/C

13 Andrion A, Magnani C, Betta PG, Donna A, Mollo F, 
Scelsi M, et al. Malignant mesothelioma of the pleura. Consistency of the histopathological diagnosis and interobserver variability. $\mathcal{F}$ Clin Pathol 1995 (in press).

14 Jones JSP, Lund C, Planteydt HT. Diffuse malignant mesothelioma. In: Jones JSP, ed. Colour atlas of Mesothelioma. Lancaster: MTP Press, 1985.

15 Huncharek M. Changing risk groups for malignant mesothelioma. Cancer 1992;69:2704-11.

16 Istituto Ricerche Economiche e Sociali (IRES). Internal report on the estimated population by age, sex and town. report on the estimated
Torino: IRES, 1988.

17 Smith PG. Comparison between registries: age standardised rates. In: Parkin DM, Muir CS, Whelan SL, Gao ised rates. In: Parkin DM, Muir CS, Whelan SL, Gao Y-T, Ferlay J, Powell J eds. Cancer incidence in five conti-
nents. Vol VI. Lyon: IARC 1992. (IARC Sci Publ No 120.)

18 Crosignani $P$, Gatta G, Sant M, Viganò C, Speciale D, Colombo G, et al. Registro Tumori LombardiaProvincia di Varese. In: Zanetti R, Crosignani P, eds. II cancro in Italia. I dati di incidenza dei Registri Tumor 1983-7. Torino: Lega Italiana per la Lotta contro i
Tumori-Associazione Italiana di Epidemiologia, 1992: 268-83.

19 Vercelli $M$. I tumori della pleura. In: Zanetti R, Crosignani $\mathrm{P}$, eds. Il cancro in Italia. I dati di incidenza dei Registri Tumori 1983-7. Torino: Lega Italiana per la Lotta contro Tumori-Associazione Italiana di Epidemiologia, 1992: 179-81.

20 Boutin C, Rey F. Thoracoscopy in pleural malignant mesothelioma: a prospective study of 188 consecutive patients. Cancer 1993;72:389-93.

21 Andrion A, Betta PG, Donna A, Magnani C, Mollo F, Scelsi M, Terracini B. Observer variability in the interpretation of histological and immunohistochemical feapretation of histological and immunohistochemical fea-
tures of malignant mesothelioma [abstract]. Path Res

22 Zanetti $\mathrm{R}$, Crosignani $\mathrm{P}$, eds. Il cancro in Italia. I dati di incidenza dei Registri Tumori 1983-7. Torino: Lega Italiana per la Lotta contro i Tumori- Associazione Italiana di Epidemiologia, 1992:94-5.

23 Busto I. Ricostruzione del ciclo produttivo dell'Eternit. Bollettino Associazione Esposti Amianto 1990;4:7-11.

\section{Instructions to authors}

Three copies of all submissions should be sent to: The Editor, Occupational and Environmental Medicine, BMJ Publishing Group, BMA House, Tavistock Square, London WC1H 9JR, UK. All authors should sign the covering letter as evidence of consent to publication. Papers reporting results of studies on human subjects must be accompanied by a statement that the subjects gave written, informed consent and by evidence of approval from the appropriate ethics committee. These papers should conform to the principles outlined in the Declaration of Helsinki (BMF 1964; ii:177).
If requested, authors shall produce the data on which the manuscript is based, for examination by the Editor.

Authors are asked to submit with their manuscript the names and addresses of three people who they consider would be suitable independent reviewers. They will not necessarily be approached to review the paper.

Papers should include a structured abstract of not more than 300 words, under headings of Objectives, Methods, Results, and Conclusions. Please include up to three keywords or key terms to assist with indexing. 